\title{
Management Curriculum between Theory and Practice
}

\author{
Josip Mesaric \\ Josip Juraj Strossmayer University, Osijek, Croatia \\ mesaric@efos.hr \\ Joze Kuzic \\ Monash University, Melbourne, Australia \\ joze.kuzic@monash.edu \\ Zdravko Dovedan \\ University of Zagreb, Zagreb, Croatia \\ zdovedan@hotmail.com
}

\begin{abstract}
The boom in business schools and schools of management in the European and world formal and informal educational area on the one hand and poor, sometimes even catastrophic, effects of managerial practice on the other hand, initiate the necessity to reviewing the existing general management curricula. Curricula of many educational institutions with long tradition in management education have undergone this process recently, as well as those institutions that have designed their curricula recently and under socio-economic conditions that were significantly different from contemporary conditions. The analysis of general management curricula in twenty business schools and schools of management at bachelor level and twenty eight schools at graduate and master level indicated that there is no generally accepted management curriculum. Furthermore, curricula have been developed in different contexts and from different starting points and different ends and means. By analysing general characteristics of managerial knowledge, we have researched curricula through some existing models and approaches to their development (curriculum as BOK to be transmitted, curriculum as a product, curriculum as development and process). Starting with specificities of managerial education and the approach to curriculum development, we have introduced a new model for curriculum design through multidimensional prism. This model can be used when analysing and revising the existing general management curricula.
\end{abstract}

Keywords: general management, curriculum, integrated model, hexagonal prism model.

Material published as part of this publication, either on-line or in print, is copyrighted by the Informing Science Institute. Permission to make digital or paper copy of part or all of these works for personal or classroom use is granted without fee provided that the copies are not made or distributed for profit or commercial advantage AND that copies 1) bear this notice in full and 2) give the full citation on the first page. It is permissible to abstract these works so long as credit is given. To copy in all other cases or to republish or to post on a server or to redistribute to lists requires specific permission and payment of a fee. Contact Publisher@InformingScience.org to request redistribution permission.

\section{Introduction}

Significant changes have occurred in the European education area, especially in the higher education area during the last decade. The ultimate goal of these changes (the Bologna Declaration) is to harmonise knowledge and to promote the mobility of stakeholders (educators and learners), which resulted in consid- 
erable changes in the existing curricula, as well as the introduction of a number of new curricula. The first products of the five-year educational cycles have been obtained recently, which has led to numerous discussions on the curricula applied and the necessities of their change and adaptation.

New courses of study at the existing universities and faculties have been developed as a result of the Bologna processes, as well as new (often private) courses of study. The number of new courses has primarily increased in the domain of economics and management, which is not a feature of only European higher education. These trends can be observed in the higher education all over the world.

The boom in higher business schools and schools of management and economics paralleled the beginning and the escalation of the economic crisis, which had its roots in catastrophic managerial practises (lacking ethical principles and moral norms), as well as in the shortcomings of the previous economics and management curricula in higher education. Even the respectable curricula of renowned schools of management are undergoing revisions (Sloan, Yale, HBS...) by positioning their product - manager into new contextual frameworks and by assigning new roles, characteristics and demands on behaviour in various processes and with different ends and means.

There are various approaches to the development of a curriculum that can be adopted, starting with specific fields, different scopes of knowledge, various starting positions of its creators, different objectives, methodologies or ways of realisation of a curriculum, as well as potential knowledge and skills of consumers. In formal education, a curriculum usually means a formal set of knowledge that is offered (and that is expected to be chosen) in a certain educational institution (Webster, 2010). Knowledge is formed into domain sets and shaped into courses and course systems (syllabuses) that have to be realised within a certain time period and according to a certain sequence. Depending on the target group and the area it will cover, a curriculum assumes the characteristics of a recipe (a product) that has to be realised, the characteristics of a process, i.e. the ways of realisation including the participants and their roles, as well as the applied methodology and the characteristics of a practice for the realisation of the products (Smith, 1996, 2000). Furthermore, a curriculum is developed or analysed through the topic maps and ontology, since the knowledge in every curriculum is in a way categorised and classified and there are relationships among different classification categories (Dexter \& Davies, 2009; Dicheva \& Dichev, 2006; Dicheva, Sosnovsky, Gavrilova, \& Brusilovsky, 2004).

This paper illustrates the necessity of revising the existing management curricula. Furthermore, its objective is to find the best possible way to create management curricula within the context of general curricula theories and practices. Management curricula will be researched within the context of the approach to curriculum development (Kelly, 2009; Smith, 2000), to the formation of the body of knowledge to be transmitted and the approach to a curriculum as a product, a process and praxis. On the basis of advantages and disadvantages of the identified approaches and models they are based on, and taking into account specific features of managerial knowledge and management education, an integrated model will be proposed.

\section{Managerial Knowledge and Curriculum}

Although etymologically related to the ability of physical (manual) manipulation over a certain material (tangible) object with the help of tools, the contemporary term management is associated with the intellectual human work and it encompasses:

- Basic functions of management (planning, organizing, leading, coordinating, controlling, staffing, motivating, resourcing, analyzing, negotiating; all activities relate to a certain system that includes organisations (usually business organisations), things, groups, individuals, oneself, from which a useful outcome occurs). 
- Formation of business policy - integrating the previous functions within given economic, ecological, legal, social ... conditions of the environment.

- Implementations of policies and strategies (operational, tactical, strategic).

- Formatting multidivisional management hierarchy.

- General and specific knowledge of single management areas.

- Methodological concepts and lifecycles of objects under management.

The attributes of managerial knowledge are the results of the change and the acquisitions of various paradigms within managerial practice and academic community. The stated basic functions are complex tasks and will differently reflect in different contexts. Their realisation is possible by forming hierarchical management structures, which are still under the influence of the old functional structures. Therefore, financial management and marketing management will not demand the same quantities and the same types of basic functions of management.

What is the objective of those who offer general management in their syllabus? Do they intend to use always the same body of knowledge to manage any object (in this case any type of business organisation, institution, occurrence, or other object under management)? Managers educated on beliefs that organizations have more similarities than differences and that generic management skills are sufficient to manage any kind of organization made "the practical achievements of the framework which made these promises have so far been small, the costs high, and the means employed controversial" (Considine, 1997). So the term used for general management in a derogatory sense got the name managerialism.

Characteristics of domain knowledge influence the model to be used in curriculum design. Specificity of managerial knowledge which influence creation and maintenance of managerial curriculum are described in further.

According to its general characteristics, managerial knowledge belongs to the group of so-called social sciences, therefore using the methods of hypothesis, analysis, conclusion and prediction. The problem characteristic for social sciences is that occurrences cannot be explained by using only rational assumptions and causal methods that are used in natural sciences. Managerial knowledge is paradigmatic for the most part. This means that in a certain socio-economic context this knowledge, founded on generally accepted theories and assumptions, is taken as good enough in managerial practice, which implies tacit acceptance of underlying theories and assumptions. Managers "obsessed as they are with the "real world" and sceptical as most of them are of all theories, and in such a manner "are no exception to the intellectual slavery of the "practical men" (Ghoshal, 2005). Even starting with unclear assumptions, partial analyses and unsubstantiated conclusions, management practice has proved to be acceptable (according to some generally accepted, current benchmarks of management performances). This creates new managerial paradigms, turning scientific management into pretence of knowledge. Therefore, even without adequate methodological apparatus and firm "scientific" arguments, these "new insights" become truth claims and grow to be a part of management practice encouraged by the interests of capital, political or some other interest. When "validated" in practice, this knowledge becomes a "case study" and, by self-fulfilment, a new paradigm without a consensus being reached on it beforehand. This raised some concerns among several scholars about the current state of management research and pedagogy (Donaldson, 2002; Ghoshal, 2005; Mintzberg \& Gosling, 2002).

Management practice is determined by "new" management theories, whereby a process of double hermeneutics occurs (Ghoshal, 2005). This double hermeneutics has led to both diverse interpretations of "management theories" in practice and different interpretations of validity of underlying theories in "scientific management" within academic circles. The problem with hermeneutics occurs due to interpretations that rely on various starting points: intentional, economic, legal, ethical, aesthetical and strategic. 
The processes of continuous reconstructions of management curricula at universities with longstanding practice are partly the result of these general characteristics of managerial knowledge.

One example is the Yale integrated MBA curriculum, which is based on the following approach: the introductory part Orientation to Management offers several courses that focus on fundamental concepts in economics, accounting, individual problem framing, managing groups and teams, and spreadsheet modelling, i.e. statistical tools. The program continues with highlighting the challenges a manager can encounter, in order to develop the skills and competencies a person must have to deal with such situations, maintaining his/her leadership role at the same time (organizational perspective). The international experience trips, taken after the first year of studies, complete the future managers' integrated leadership perspective. This is followed by advanced knowledge from previously taken courses and specialization in a chosen business area (http://mba.yale.edu/MBA/curriculum/index.shtml)

The problem with managerial knowledge at universities with recently introduced courses in management is only multiplied, since curricula have been borrowed and slightly adjusted to meet their demands with no additional reviews or own insights.

\section{General Management Curriculum}

In order to establish if there is a general consensus, and what is the minimum core knowledge offered (i.e. required) by general management programs at different educational levels, we have analyzed 20 general management curricula at bachelor level (8 American, 5 European and 7 Croatian) and $28 \mathrm{MBA}$ or graduate programs (12 American, 8 European, one Australian and 6 Croatian). All the courses were listed (for some universities only core, major or concentration courses, without electives) in a single MS Excel table, and then submitted to data analysis from different aspects. Alphabetical listing and additional key word searches revealed common features in general management curricula at undergraduate and graduate levels respectively.

At undergraduate level all the programs have these core (mandatory) courses: (Introductory) Management, Accounting and Marketing. Most American and European programs (11 out of 13) have also Finance, Corporate Finance or Financial Management, and for the majority ( 9 out of 13) Business Law and Human Resources Management (HRM) are also core courses.

All the Croatian universities have included Management, Marketing and Accounting as core courses, whereas 6 out of 7 have also National Economy, Microeconomics and Foundations of Economics. Most Croatian undergraduate programs (5 out of 7) have Public Finances, International Economics and Macroeconomics, but none have Business Law and Human Resources Management at this level.

At higher tertiary level (graduate and MBA) the similarities (the number of common core/major courses) are significantly decreased, whereas the number of electives is increased. Elective courses are intended to allow students to shape their managerial knowledge according to their own interests and goals. The courses with the highest common denominator at American, European and Australian programs taken together are Marketing, Leadership, and HRM (10 out of 21 universities). One third of programs offer Higher-level Accounting, Operational and Strategic Management. The remaining courses are quite varied both in titles and the areas they cover.

Graduate and MBA general management programs in the Republic of Croatia have hardly any common features. The courses that might be viewed as common appear at two universities at the most. There are also significant differences in comparison to the analyzed universities abroad.

Management study programs are distinctively divergent, encompassing a large number of courses which are different in terms of their subject matter, depth and width of study, object of management, etc. As we analyzed the course titles, the word management was found in combination with 
almost 60 different concepts. In some of those combinations the word management is superfluous, or somehow at odds with the other concept.

Unless the approach taken in designing the general management curriculum is explicitly stated elsewhere, it can be discerned from the list of courses (syllabus).

In the following part of the paper, management curriculum is observed from the standpoint of various aspects. The objective is to determine characteristics and ways of developing and finding new dimensions necessary for establishing a thorough and consistent methodology of its development.

\section{General Management Curriculum as a Body of Knowledge - Syllabus to Be Transmitted}

Many contemporary curricula are based on the idea of forming a body of knowledge (IS BOK, US MBOK, PM BOK).

The body of knowledge of a curriculum is formed on the basis of desired knowledge, abilities and skills that a knowledge holder should possess. Managerial competencies and skills should enable knowledge holders to do the following:

- recognise reality, determine objectives and their accomplishment in an effective way within the given sociological, economic and technological context;

- create new values that will be used, due to the knowledge they posses, to anticipate and create situations in which the acquired knowledge will give an undisputable advantage;

- find solutions to problems which will happen (negative context in which new values are not created), but whose purpose is to minimise any "costs" or negative effects that a managed "system" develops upon itself and the environment within which it happens;

- follow the trends (socio-economic, technological, aesthetical, ethical...) in the area of own management and in the general environment;

Experiential knowledge and anticipatory knowledge are used to form "concise statement or table of the heads of a discourse, the content of treatise, the subject of series of lectures" (Smith, 2000) which are formed into courses that lead towards exams as a verification of the acquired knowledge. The totality of content and inherent pedagogy form syllabuses - prescriptions according to which knowledge will be transferred to their future users and be verified within a certain context. The body of knowledge and the contents of single courses represent trade-offs that are a result of the scope of knowledge and the experience of creators themselves, the time span within which they should be transferred, anticipated knowledge and experience of recipients and desired objectives. Therefore, significant differences among management syllabuses (curricula) can be observed due to general and specific characteristics of managerial knowledge.

The body of knowledge of general management does not exist. The closest to the sum total body of knowledge of general management was formed in the Universal Services Management Body of Knowledge (Clayton, 2008), while Project management BOK, Business process Management BOK, Knowledge management BOK, Data Management BOK are narrower areas of general managerial knowledge. The curricula of general management should include fundamental managerial knowledge, generic managerial knowledge and specific knowledge areas that should be balanced in their scope, sequence and time to be transferred to their users.

\section{Management Curriculum as a Product}

In contemporary higher education a curriculum represents a set of knowledge shaped into a university programme - a set of courses that is usually realised through an intensive training within 
two, three or more years of study. Single courses are realised in a half-semester or a semester at most. Thus "education is most often seen as a technical exercise. Objectives are set, a plan drawn up, then applied and the outcomes (products) measured" (Kelly, 2009).

This approach to a curriculum stems from the period of "scientific management" in the first half of the previous century. It was significantly influenced by F. W. Taylor who was trying to simplify jobs and lower production costs by studying movement and time, as well as what individuals have to learn (which competencies they have to acquire) to maximise the efficiency in performing their tasks. Furthermore, the control of workers' performance by the management should also become simplified and maximally efficient.

"General management curriculum" does not exist, nor does a professional association (as in the case of project management, IS, service management, etc.) that will offer a curriculum which will be accepted and realised as a product by an educational institution. General management curricula have been developed by higher education institutions through their cooperation with the business surroundings, thus there are no two identical "management curricula" in the world, similar either in their content or in their level of education or the time needed for the realisation of a curriculum.

Within the context of this approach (one that is very similar to the technical or productive thinking), a curriculum is designed by using the following procedure: (Smith, 2000)

Step 1: Diagnosis of need.

Step 2: Formulation of objectives.

Step 3: Selection of content.

Step 4: Organization of content.

Step 5: Selection of learning experiences.

Step 6: Organization of learning experiences.

Step 7: Determination of what to evaluate and of the ways and means of doing it.

Taba (1962) emphasises that "central to the approach is the formulation of behavioural objectives - providing a clear notion of outcome so that content and method may be organized and the results evaluated"(Smith, 2000). According to this approach, a curriculum can be seen as: "a programme of activities (by teachers and pupils) designed so that pupils will attain so far as possible certain educational and other schooling ends or objectives" (Grundy,1987). This is basically true, but the unanswered issue is how to define the needs and consequentially how to define the ends (objectives) that will meet their requirements.

The logic of this approach is for the curriculum to be designed outside of the classroom or school, which is not the case for the schools of management. But, as we have emphasised, not all schools of management have the same tradition. Experience shows that the curricula of more recent schools have been borrowed and adapted to the given internal structures of a higher education institution and the current economic practice. It is highly important that the demands in the form of the "product" - manager with the required competencies, that has been "produced" and educated according to the management curriculum product come from outside and that the quality of the "product" cannot be objectively measured by the sum of partial grades of a realised programme. This points to the second problem of this approach, namely evaluation. In order to measure, things have to be broken down into smaller and smaller units. "The result, as many of you will have experienced, can be long lists of often trivial skills or competencies. This can lead to a focus in this approach to curriculum theory and practice on the parts rather than the whole; on the trivial, rather than the significant" (Smith, 2000). This is of utmost importance nowadays, when we exceedingly fragmentise but not synthesise, not only managerial knowledge. What we are inclined to measure, such as achievements in any university curriculum, has been more than often reduced to the quality of interpretation. Successful interpreters frequently fail to manipulate 
their knowledge in real life, which is often the case with managers due to the paradigms acquired over several years of education, when in practice such paradigms tend to change rapidly. The use of the acquired, but no longer relevant paradigms will result in poor performance of managerial knowledge in practice.

Smith points to the third problem of this approach, "a real problem when we come to examine what educators actually do in the classroom". Much of the research concerning teacher thinking and classroom interaction, and curriculum innovation has pointed to the lack of impact on actual pedagogic practice of objectives (Cornbleth, 1990; Stenhouse, 1974).

The fourth problem of this approach indicated by Smith is the problem of unanticipated results. The focus on pre-specified goals may lead both educators and learners to overlook learning that is occurring as a result of their interactions, but which is not listed as an objective. Two scenarios are possible: if you evaluate an educator only by the achievements (the goals) of a curriculum, only successful interpreters (learners) of current (assigned literature) can do exceptionally well, which is often the case with the educators - "theoretical" managers that dominate some universities. The wealth of experience that is not anticipated in the curriculum transferred by educated managers with practical expertise in informal types of education is rarely or never measured when evaluating an educator.

Managers educated on a curriculum designed along these lines will prove to be better or poorer interpreters of the knowledge thus gained, but their capacity to solve real-life problems and to create new value will be limited.

\section{Management Curriculum as a Process and Development}

According to Stenhouse (1975), "A curriculum is an attempt to communicate the essential principles and features of an educational proposal in such a form that it is open to critical scrutiny and capable of effective translation into practice". Although he does not state that curriculum is a process, Stenhouse emphasises that "as a minimum, a curriculum should provide a basis for planning a course, studying it empirically and considering the grounds of its justification" on the basis of clear principles and guidance.

A process is generally characterised by changes in the time of a system or some of its features, initiated by events, participants, their roles, states or results.

Curriculum as a process 'is a way of translating any educational idea into a hypothesis testable in practice. It invites critical testing rather than acceptance' (Stenhouse, 1975). At first glance, this is an ideal model desired by managers. Nevertheless, at least two problems may occur.

The first problem is the experiment with the socio-economic systems and the nature of realising managerial decisions. A system where an idea, hypothesis or decision can be tested within a reasonable time period and with acceptable consequences simply does not exist, since it is not possible in a certain moment (a phase of a business cycle) or it can trigger unexpected, risky or adverse consequences. The use of mathematical models and simulation techniques or managerial simulation games is more and more becoming a key to these problems. Their shortcoming is that they have to simplify reality and are, as a rule, often directed towards the problems in managerial efficiency, i.e. only certain functions of management. It is not easy to conduct an experiment in social studies, as well as in management. One can try different simulations, managerial games, mathematical models, but with paradigmatically-oriented knowledge, a problem arises with the origin and the content of the paradigm and its manifestation within systems of different levels of socio-economic and cultural development.

This approach to the theory of curriculum, because it places meaning-making and thinking at its core and treats learners as subjects rather than objects, can lead to very different means being em- 
ployed in classrooms and a high degree of variety in content. As Stenhouse comments, the process model is essentially a critical model, not a marking model (Stenhouse, 1975).

Along with its advantages, this model has some unsolved issues (Smith, 2000):

- a problem for those who want some greater degree of uniformity in what is taught,

- it may not pay enough attention to the context in which learning takes place

- it rests upon the quality of teachers

- it does not make explicit the commitments associated with phronesis.

From the aspect of management curriculum as a process and development, it is necessary to address the problem of "grounds of its justification" (a formulation of the intention or aim of the curriculum which is accessible to critical scrutiny.)

"Ground of justification" should primarily begin with the anticipated requirements of the environment, simply since graduates find their first jobs within the wider area of their study, but this is not often the case. We do not know the exact requirements, but we hope that the adopted curriculum will be good enough and sufficiently flexible to serve most of the requirements that might arise in the future.

\section{Curriculum as Praxis}

Although Smith underlines that this model (the approach to curriculum development) is extension of a curriculum as a process and development, he emphasises that "in this approach the curriculum itself develops through the dynamic interaction of action and reflection. At its centre is praxis: informed, committed action (Smith, 2000).

Management curricula have been influenced by the general corporatisation of colleges in the last twenty years. Parker emphasises that "the findings reveal an underlying neoliberal political and economic agenda that has laid the foundations for the profound transformation that has reconfigured universities' governance, missions, core values and the roles of their academics. These changes emerge as mimicking private sector corporate philosophies and governance structures, as well as returning to scientific management approaches of a century ago" (Parker , 2010). Particularly for state owned and funded universities in the public sector, these changes not only represent dramatic reconstitutions of philosophy and societal roles, but reflect fundamental forces that are not always entirely understood or fully appreciated.

Kelly points to another problem when curriculum comes to praxis, i.e. curriculum externalisation and it is its politicization (Kelly, 2008). Although this problem is closely related to primarily those curricula that are imposed from the outside and that imply the positions of the political elite, general management curricula are, in some of its parts, susceptible to politicization. Namely, there is no business system that functions exclusively on the basis of market, i.e. economic legitimacy. Paradigms and behavioural patterns of political elite have been built into their business activities, along with their accepted behavioural norms and value systems. General and specific management curricula will be politicized in exchange relationships via acquired paradigms of the schools of management and business environment within which they operate.

\section{Developing and Analysing General Management Curriculum through a Hexagonal Prism}

Indisputably, each model of approach to the general management curriculum development reveals some of its aspects and assists with the development of this complex curriculum. There is no single theory according to which a curriculum was formed at any of the numerous world schools of 
management (business). This indirectly indicates that "the choice among theories, then, falls very much on scholar's personal preferences rather than on either the discipline of empirical estimation or the rigor of formal, deductive logic. Combined with possibility of self-fulfilling prophecy, it is this ambiguity between good and bad theories" (Ghosal, 2005).

Although, in principle, in every curriculum there is something that is considered to be a key, or fundamental, set of knowledge on the one hand and a broadly-defined set of specific knowledge on the other hand, it is certain that managerial knowledge as a paradigm has been developed on the basis of other paradigmatic disciplines. These disciplines are now being assigned different functions and contexts (economics and managerial economics; accounting and managerial accounting; finance and managerial finance; marketing and marketing management, etc.).

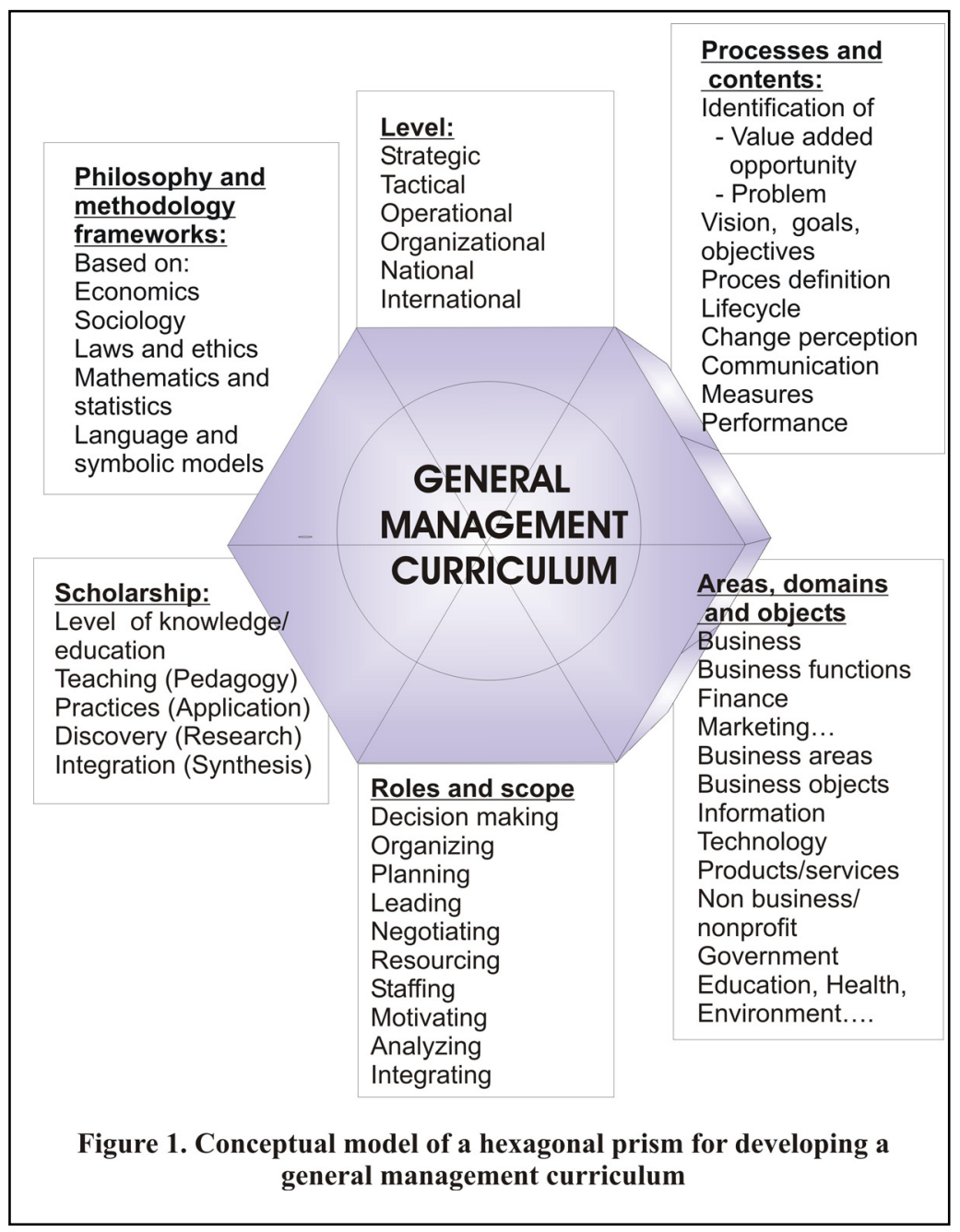

The majority of high-ranking business schools, besides MBA programs, have EMBA (Executives MBA) for practitioners and their training in some aspects of management, which serves as a proof of continuous revision of managerial knowledge and changes in its scope, methodology, areas of application, objects and managerial roles and tasks.

Due to general characteristics of these approaches to the development of a curriculum so far, as well as the specificities that these approaches have in the development of a management curriculum, a more complex, more inclusive and multidimensional approach is becoming necessary.

In the following text a new model is proposed for the development and analysis of general management curricula, encompassing all the necessary elements for curriculum design and analysis. It is called the hexagonal prism model, as each side of the prism is one aspect that elucidates the curriculum through elucidating other aspects, as they are all interdependent. The static model of this approach is shown in Figure 1. 
The idea of stacked prisms stems from optics. A ray of light directed at the prism will pass through it, break and reflect in various ways, reaching borderline areas as well as the point of entry. Figure 2 provides an example of how the "rays" of composite "light" ROLES AND SCOPE can be manifested in the prism they belong to and the surrounding prisms. In creating a curriculum this would mean the following: if it is accepted that six prisms can satisfactorily represent the aspects from which a curriculum is to be viewed, we shall begin with the prism ROLES AND SCOPE. This prism focuses on the purpose of a concrete educational program and the roles to be assumed by students after graduation.

The idea of stacked prisms stems from optics. A ray of light directed at the prism will pass through it, break and reflect in various ways, reaching borderline areas as well as the point of entry. Figure 2 provides an example of how the "rays" of composite "light" ROLES AND SCOPE can be manifested in the prism they belong to and the surrounding prisms. In creating a curriculum this would mean the following: if it is accepted that six prisms can satisfactorily represent the aspects from which a curriculum is to be viewed, we shall begin with the prism ROLES AND SCOPE. This prism focuses on the purpose of a concrete educational program and the roles to be assumed by students after graduation.

An individual role is taken as a constant which is analyzed in the context of content of other prisms.

The content of the initial prism is discussed in terms of the necessary volume. For the role of "leading" the first question will be whether the volume of knowledge (depth and width) for this role necessitates so much knowledge and time that it has to be put in a separate course. If the answer is affirmative, the next thing to consider is the level of education. The prism of Scholarship serves to assess the capacities of the institution, the prism of Philosophy and Methodology will reveal the required general and methodological knowledge, the prism Processes and Contents will establish process orientation and necessary content, whereas the prism Level and the prism Areas and Domain will be used to consider the level and the areas in which the developed curriculum can satisfy the needs and requirements of its particular environment. This is a recursive process, which means that certain aspects can have an impact on other aspects in the same prism. 
It might be too complex and time-consuming to design a new curriculum on the basis of the model proposed here. Due to comprehensive analysis of a large number of interdependencies it could be relatively difficult to achieve consensus within the team which is assigned the task of creating the curriculum. However, the model has proved to be quite useful in the analysis of existing curricula. It was used specifically to analyze the general management curriculum on bachelor degree at one Croatian university, highlighting its advantages and disadvantages, which will certainly be taken into account during its forthcoming revision. By using this model we found out that:

- Emphasize on key managerial roles was given to the organization, decision making and staffing, while other roles (planning, leading, analyzing, negotiating and integrating ) are postponed;

- Level (weights) of knowledge is not clearly defined at this level of education and methodological knowledge is dominated;

- Curriculum is unbalanced because it has much of obligatory courses in "Philosophy and Methodology" prism with to much emphasize on economies of all scope and levels (principles of economics, microeconomics, macroeconomics, national economics, urban economics) but without any emphasize on law and ethics. Accounting, marketing, statistical and mathematical basis and foreign language are also included in this prism;

- Managerial level is considered only at regular business organization level;

- Process orientation is perceived only in new value creation (course Management of new product) and communication (course Business communication), but problem orientation, analytical skills, performance measures are neglected

- Managerial areas, domains and objects, (although issues of higher level of education or specialization), defined in separate courses cover one business area (Insurance Management) and one business function (Financial management)

These few general findings are clear indices that some improvements need to be done in analyzed curriculum. Detail analysis according to the procedure mentioned earlier will reveal other inconsistencies and points of curriculum that need to be improved, with suggestions how and where that improvement needs to be done.

\section{Concluding Remarks}

The analysis of numerous general management curricula created by different business schools and schools of management has shown that there is no one common, universally accepted general management curriculum - neither in terms of content or in terms of educational level, regardless of the geographical location of the schools. It seems that European and American business schools agree that undergraduate programs should include general education in management, accompanied by basic knowledge in accounting, marketing, human resources management, business law, and business finances. At universities with a shorter tradition of managerial education, such as Croatian universities, there are other core courses in addition to principles of management, accounting and marketing. An important role is given to foundations of economics, microeconomics, national economy and macroeconomics, but not to business law, human resources or business finances. The differences at higher levels of education are of such a scope that it becomes difficult to recognize the common features of general management programs at different graduate and MBA schools.

Even though the majority of curricula have been formed according to a certain philosophy of approach and their content according to the core and electives principle, there is no single philoso- 
phy for the approach to the curriculum development; management curriculum is basically a curriculum within a context.

The approaches to general management curriculum development contain elements of each researched model. The body of knowledge to be transmitted, closely resembling BOK general management, is contained in Universal service management BOK. PM BOK is the most well-known and cited, while Operation management body of knowledge belongs within a wider context. These BOKs belong to the subcategories of BOK general management.

Although they do not explicitly contain BOK according to which they were formed, syllabuses (programs and lists of courses) or as they are often replaced by the term curricula, have some general and/or specific starting points on the basis of which curricula are formed. Some of them are distinguished by their product approach, usually those of less prominent schools with shorter tradition in managerial education.

The approach to a curriculum as a process is more frequent in schools with longer tradition. The model of curriculum development as praxis is becoming a dominant approach in most schools. This approach is characterised by the use of case methods as teaching methodology and by practical work during studies. In most cases, schools are becoming internationalised. Despite the fact that schools enjoy complete freedom in creating their curricula, tendencies towards corporatisation of business schools and schools of management are becoming increasingly noticeable.

Management curricula depend on the context and not on some acquired scientific theories nor generally accepted philosophical concepts; general management is not the same in all environments and its contents on the one hand and its realisation on the other hand strongly depend on the institution and its social, economic and cultural environment, as well as strategic objectives and positions of the institution - the school of management.

The fact that managerial knowledge is paradigmatic can be noticed not only on the level of a curriculum, but also on the level of individual courses of the same or similar title with considerably different contents.

The fundamental functions and roles of management (planning, organising, leading, coordinating, controlling, staffing, motivating, resourcing) are in some cases designed as separate courses which implicitly emphasises the importance of some aspect of managerial function, but at the same time makes that general management curriculum unbalanced.

There are many cases where it can be noticed that curricula do not aspire to become overly scientific (without causal methods, mathematical-statistical apparatus and robust evidence), so that it seems (to paraphrase Ghoshal) that "business could not be treated as a science, and we would have to fall back on the wisdom of common sense that combines information on "what" is with the imagination of "what ought to" to develop both a practical understanding of and some pragmatic prescription for "phenomena of organized complexity" that the issue of corporate governance represents. This too is scholarship, but yields theory that does not pretend to be scientific laws but merely serves as temporary "walking sticks" in Fritz Roethlisberger's (1977) terms - to aid sense making as long as we go along, to be used only until a better walking stick can be found (Ghoshal, 2005).

This paper offers a new model approach to curriculum development and analysis through the use of a hexagonal prism. Its purpose is to elucidate management curriculum from every necessary aspect. This is an integrated approach to the development and analysis of a general management curriculum. It might be useful in shaping valid classification categories, thus developing complete, balanced and detailed curricula and syllabuses in institutional formal and informal educational systems of general management at different levels of education. Model proved it to be useful in analysis of existing curricula and revealing its advances and shortcomings. Model was vali- 
dated in currirulum analysis and now should be validated in design of some managerial curriculum according to the main dimensions it covers.

\section{References}

Clayton, I. M. (2008). Universal services management body of knowledge. Retrieved October 26, 2010 from http://www.usmbok.org/usmbok map.html

Cornbleth, C. (1990) Curriculum in context. Basingstoke: Falmer Press.

Considine, M. (1997). Managerialism strikes out. In M. Considine \& M. Painter (Eds.), Managerialism: The great debate (pp. 88-112). Melbourne University Press. Retrieved from http://business.highbeam.com/137662/article-1G1-54905585/managerialism-great-debate

Curriculum. (n.d.). Retrieved February 19, 2010 from http://en.wikipedia.org/wiki/Curriculum

Dexter, H., \& Davies, I. (2009). An ontology-based curriculum knowledgebase for managing complexity and change.Ninth IEEE International Conference on Advanced Learning Technologies, 2009, icalt, pp.136-140.

Dicheva, D. \& Dichev, C. (2006). TM4L: Creating and browsing educational topic maps. British Journal of Educational Technology - BJET, 37(3), 391-404. Retrieved March 07, 2010 from http://compsci.wssu.edu/iis/nsdl/Publications/BJET06-Dicheva-Dichev-Submitted.pdf

Dicheva, D., Sosnovsky, S., Gavrilova, T., \& Brusilovsky, P. (2004). Ontological web portal for educational ontologies. Retrieved February 26, 2010 from http://www.win.tue.nl/SW-EL/2005/swel05aied05/proceedings/4-Dicheva-final-full.pdf

Donaldson, L. (2002). Damned by our own theories: Contradictions between theories and management education. Academy of Management Review, 15(3), 369-381.

Ghoshal, S. (2005). Bad management theories are destroying good management practice. Academy of Management Learning \& Education, 4(1), 75-91.

Grundy, S. (1987). Curriculum: Product or praxis? Lewes: Falmer Press.

Kelly, V. (2009). The curriculum: Theory and practice (6th ed.). Sage Publications.

Managerialism (n.d.). Retrieved October 30, 2010 from http://en.wikipedia.org/wiki/Managerialism

Mintzberg, H., \& Gosling, J. (2002). Educating managers beyond borders. Academy of Management Learning and Education, 1(1), 64-76.

Parker, L. (2010). University corporatisation: Driving redefinition. Critical Perspectives on Accounting (2010), doi:10.1016/j.cpa.2010.11.002).

Smith, M. K. (1996, 2000). Curriculum theory and practice. The encyclopaedia of informal education, Retrieved February 23, 2010 from www.infed.org/biblio/b-curric.htm

Stenhouse, L. (1975). An introduction to curriculum research and development. London: Heineman.

Taba, H. (1962). Curriculum development: Theory and practice. New York: Harcourt Brace and World.

Webster. (2010). Curriculum. Webster dictionary. Retrieved November 27, 2010 from

http://www.merriam-webster.com/dictionary/curriculum 


\section{Biographies}

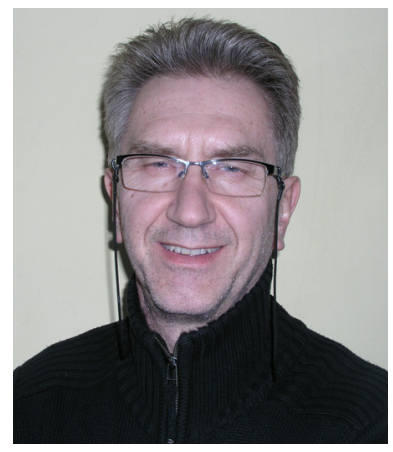

Josip Mesaric, Phd.Full professor at Faculty of Economics in Osijek. He is the Chair of Business Informatics Department. His research interests are Information system modelling, Business process management and Project Management. He is also experienced in curriculum development. Dr. Mesaric has published more than fifty scientific and professional books and papers.

Dr. Joze Kuzic Currently holds the position of the Director of Master of Business (Information Technology Management) at Monash University, Melbourne, Australia. His research interests include Information Systems, E-business, Project Management, and Applied Statistics. Dr. Kuzic has published more than 40 journal, conference papers, and book chapters.

Zdravko Dovedan, Phd. Full profesor of Faculty of Philosophy in Zagreb, Chair of Information Science Department. His main interest are Formal languages and Algorithm structures. Dr. Dovedan published eleven books and over 50 scientific and professional papers. 